\title{
Influence of osteopathic cervical manipulation on blood flow velocity of the cerebral circulation in chronic neck pain: analysis of three groups
}

\author{
Influência da manipulação osteopática cervical na velocidade de fluxo sanguíneo da circulação \\ cerebral em indivíduos com cervicalgia crônica: análise de três grupos
}

Rafael Stelle 1 , Bianca Simone Zeigelboim², Marcos Christiano Lange ${ }^{3}$, Jair Mendes Marques², François Ricard ${ }^{4}$, Cleofás Rodríguez Blanco 5

\section{ABSTRACT}

BACKGROUND AND OBJECTIVES: Spinal manipulation (SM) can reduce or improve the pain and dizziness originated in the neck. However, there is some criticism against SM. The objective of this study was to check if the osteopathic manipulation (OM) with a cervical rhythmic articulatory technique (CRAT) provides oscillations of the blood flow velocity (BFV) in the internal carotid arteries (ICA), vertebral arteries (VA) and basilar artery (BA), and if this technique is a risk factor for this circulatory system.

METHODS: The study was conducted with 73 individuals (men and women) with mechanical cervicalgia, with an average age of $37.7 \pm 6.4$ years. Fifty-eight had mild to moderate pain, randomly divided into control group (CG) and experimental-1 (EG-1), and 15 with severe pain in the experimental-2 group (EG-2). All subjects were submitted to the artery ultrasound (ICA, VA, and BA) in a blind methodology for the tests 1 (E1) and 2 (E2). Between E1 and E2, one single OM-CRAT was performed in the EGs 1 and 2 and resting for the CG.

RESULTS: In the EG-1 there was a slight reduction of the BFV in the right ICA. In the EG-2 there was a significant increase of the BFV in the right VA. All samples presented normality. In the CG there was a reduction of the BFV in the left VA. When comparing the three groups, there was significance for the CG as EG-2 of the BFV in the right ICA (in E1) and of the BFV in the left ICA (in E2).

1. Universidade Tuiuti do Paraná, Departamento de Pós-Graduaçấo em Distúrbios da Comunicação, Curitiba, PR, Brasil; Escuela de Osteopatía de Madrid Internacional, Departamento de Pós-Graduaçáo em Osteopatia, Madri, Espanha.

2. Universidade Tuiuti do Paraná, Departamento de Pós-Graduaçấo em Distúrbios da Comunicação, Curitiba, PR, Brasil.

3. Universidade Federal do Paraná, Hospital de Clínicas, Departamento de Neurologia, Curitiba, PR, Brasil.

4. Escuela de Osteopatía de Madrid Internacional, Departamento de Pós-Graduaçấo em Osteopatia, Madri, Espanha.

5. Universidad de Sevilla, Departamento de Fisioterapia, Sevilha, Espanha; Escuela de Osteopatía de Madrid Internacional, Departamento de Pós-Graduação em Osteopatia, Madri, Espanha.

Submitted in May 19, 2017

Accepted for publication in April 23, 2018.

Conflict of interests: none - Sponsoring sources: none.

Correspondence to:

Rafael Stelle

Rua Camóes, 1825 - Bairro Hugo Lange

80040-180 Curitiba, PR, Brasil.

E-mail: osteocuritiba@gmail.com

(C) Sociedade Brasileira para o Estudo da Dor
CONCLUSION: Despite the BFV oscillations, one can conclude that the OM-CRAT generates oscillation in the BFV within the normality parameters and it is not a risk factor for cerebral circulation.

Keywords: Carotid arteries, Cervicalgia, Doppler ultrasound, Neck pain, Spinal manipulation, Vertebral artery.

\section{RESUMO}

JUSTIFICATIVA E OBJETIVOS: A manipulação vertebral cervical (MVC) pode reduzir ou melhorar a dor e a tontura de origem cervical. No entanto, há críticas contra a MVC. O objetivo deste estudo foi verificar se a manipulação osteopática (MO) com técnica articulatória rítmica cervical (TARC) proporciona oscilaçóes de velocidade de fluxo sanguíneo (VFS) nas artérias carótidas internas (ACI), vertebrais (AV) e basilar (AB), e se essa técnica é um fator de risco para esse sistema circulatório.

MÉTODOS: A casuística foi constituída de 73 indivíduos (homens e mulheres) com cervicalgia mecânica, com idade média de 37,7 $\pm 6,4$ anos, sendo 58 com dor leve a moderada, divididos por aleatorização em grupos controle (GC) e experimental-1 (GE-1), e 15 com dor intensa no grupo experimental-2 (GE-2). Todos foram submetidos à ultrassonografia arterial (em $\mathrm{ACI}, \mathrm{AV}$ e $\mathrm{AB}$ ) em metodologia encoberta para os exames 1 (E1) e 2 (E2). Entre E1 e E2 foi realizado única MO-TARC para os GE 1 e 2, e repouso para o GC.

RESULTADOS: Em GE-1 houve pequena redução de VFS da ACI direita. Em GE-2 houve aumento significativo de VFS na AV direita. Todas as amostras apresentaram normalidade. Em GC houve redução de VFS da AV esquerda. No comparativo entre os três grupos houve significância para o GC como GE-2 na VFS da ACI direita (em E1) e na VFS da ACI esquerda (em E2). CONCLUSÁO: Apesar das oscilaçôes de VFS, concluiu-se que a MO-TARC gera oscilação de VFS dentro dos parâmetros de normalidade e não é um fator de risco para a circulação cerebral. Descritores: Artérias carótidas, Artéria vertebral, Cervicalgia, Dor de pescoço, Manipulação da coluna, Ultrassonografia Doppler.

\section{INTRODUCTION}

Cervical spine pain of mechanical origin is a common condition, represented by pain and range of motion (ROM) limitation, sensitivity or neck muscles tenderness, and can become chronic or recurrent ${ }^{1,2}$. This condition can be related to repetitive movements, inadequate posture during work activity ${ }^{3}$ or be induced 
by trauma or whiplash injury ${ }^{4}$. This can cause microtraumas on the cervical vertebrae and myofascial periarticular tissues ${ }^{1,2}$. If these injuries are followed by an articular vertebral restriction, it can be called vertebral somatic dysfunction, which induces the sensitization of the neural circuit, associated to the sympathetic hyperactivity, increase in vascular tone, and myofascial tensions ${ }^{5,6}$. Neck pain by mechanical dysfunction can alter the posture control system and create a body imbalance (sensation of instability or dizziness), due to the relationship with the central nervous system, proprioceptive afferents of the somatosensorial system, vestibular system, control of eye movement and the vi$\operatorname{sion}^{7,9}$. However, the body imbalance is usually attributed to the visual system and labyrinth disease $e^{8,9}$, or even to the vertebrobasilar insufficiency, which can be confirmed by cervical flexion-rotation clinical tests ${ }^{10.11}$ and by vascular ultrasound that checks the blood flow velocity (BFS) of the internal carotid arteries (ICA), vertebral arteries (VA) and basilar (BA $)^{5,12}$.

On the other hand, in individuals with common neck pain, the VA, BA and ICA blood flow is not impaired by the rhythmic osteopathic manipulation of the cervical spine ${ }^{5}$.

The objective of the osteopathic manipulative treatment (OMT) is to treat the vertebral somatic dysfunctions or vertebral hypomobilities that can be among the causes of neck pain, posture alteration, cervical-related dizziness, some headaches, etc. ${ }^{5,6,13-17}$. It is possible to have oscillations after a cervical vertebral manipulation, sometimes with an increase in the $\mathrm{BFS}^{5,15,16}$, an improvement in muscle strength and enduranve ${ }^{17}$, increase in cervical ROM, and reduction of cervical pain ${ }^{6,13}$ and headache ${ }^{18}$. Among the several osteopathic manipulation (OM) techniques is the cervical rhythmic articulatory technique (CRAT) with rotation and sliding $5,6,15$.

The dissection of the VA associated with the cervical vertebral manipulation is rare; however, according to some references, it can be serious or fatal in some cases ${ }^{19-21}$. However, there are reports that the cervical vertebral manipulation and the cervical mobilization do not present a vascular risk to vertebral and carotid arteries ${ }^{5,22-24}$, and that this technique can provide normal oscillations or a slight increase in BFS5. The VA dissection should be attributed to the mechanical impact, as whiplash trauma, and not to the cervical vertebral manipulation ${ }^{23}$. In general, the dissection of the carotid arteries is usually attributed to the car accidents, being a rare consequence of the cervical vertebral manipulation ${ }^{21}$.

However, OM-CRAT stimulates BFS oscillations of the cerebral arteries (ICA, VA, and BA) within the parameters normality, and it can activate or increase the cerebral circulation ${ }^{5,15}$.

The objective of this study was to investigate if the CRAT with rotation and sliding influences the oscillations (increase or reduction) of the BFS of the ICA, VA, and BA comparing three groups with neck pain.

\section{METHODS}

The study was randomized, blind, and controlled, with a comparative analysis of three groups. The study population was of 73 individuals (men and women), as follows: 58 individuals (18 men and 40 women), with average age of $36.0 \pm 6.5$ years (men: $36.5 \pm 6.1$ years; women: $34.8 \pm 7.3$ years) with chronic, mild and moderate mechanical neck pain; and 15 individuals ( 2 men and 13 women), with average age of $37.7 \pm 6.4$ years (men, $38.3 \pm 6.7$ years, women, $34 \pm 1.4$ years) with severe chronic mechanical neck pain (but, not unbearable or disabling), complaining about occasional and mild dizziness. The level of pain was classified according to the Neck Disability Index - section 1 . The volunteers were employees of the General Hospital of the Federal University of Paraná.

The sample of 73 patients corresponds to a confidence level of $90 \%$, and sample error of $6.5 \%$, that can vary for more or less.

The division of the groups was carried in the following way: the group with 58 individuals with mild to moderate neck pain was randomized into a control group $(\mathrm{CG} n=29)$, and experimental group-1 (EG-1 n=29). The experimental group-2 with severe neck pain (GE-2 $\mathrm{n}=15)$ was in a sequential form.

The period of the study was from August 2010 to March 2012, and from March to August 2013.

The methods were always carried by the same professionals, one operator- 1 blind for the ultrasound, and operator- 2 for rest control and execution of the OM-CRAT. The individuals were analyzed by vascular ultrasound at two moments, blind and sequential, for the ICA, extra and intracranial VA and BA, including test 1 (E1) and test 2 (E2). The E2 occurred after resting in the CG, and after OM-CRAT in the EG. The procedures were performed in a single session of approximately 20-25 minutes for each subject. After the interview, the data collection and the signature of the Free and Informed Consent Form (FICT), the subject was positioned in the supine position on a stretcher, with the head on a small and low pillow (children-like), remaining in a quiet environment until the end of the procedures, that followed this sequence:

1. Ultrasound (E1) ( $\mathrm{n}=73)$;

2. Rest in CG (n=29)/and OM-CRAT in EG-1 (n=29) and in EG-2 ( $\mathrm{n}=15)$;

3. Ultrasound (E2) (n=73).

The inclusion criteria were individuals with age between 25 and 45 years, of both genders, not taking medication. The CG and the EG-1 had healthy individuals and could include chronic common neck pain, of mild and moderate intensity, and with some cervical ROM limitation. The EG-2 had individuals with chronic common neck pain, intense pain, and some cervical ROM limitation. The intensity of pain was considered according to the Neck Disability Index.

The exclusion criteria were any alteration that could preclude the protocol fulfillment, as unbearable or disabling pain, moderate or important dizziness or vertigo; or other signs of vertebrobasilar failure during the procedures, change of blood flow in the first ultrasound of the protocol, cervical hypomobility (e.g.: spondylosis, bone malformation, spine deformity as Scheuermann's disease), individuals in post-operative stage, sequel by cranial or spine trauma, using crutches, a walker or wheelchair.

\section{Vascular ultrasound}

The ultrasound was performed in the three groups by the same researcher with the blind method (operator-1). The ultrasound device model was VIVID, from GE, with a linear transducer 
of 7.5 to $10 \mathrm{MHz}$ for extracranial circulation, and a transversal transducer of 1.5 to $5 \mathrm{MHz}$ for intracranial circulation ${ }^{5}$. Tests 1 and 2 were performed (E1 and E2), for 3 minutes each. Soon after each test, operator- 1 left the room and returned 5 minutes later for the next step. After the routine examination to evaluate abnormal findings in the carotid and vertebral, and absence of pathological changes, the samples of the arterial Doppler for the right ICA (RICA), left ICA (LICA), VA (RVA) and left VA (LVA), RCA in its intracranial segment (RCA Intra), LVA in its intracranial segment (LVA Intra) and BA were saved. The direct analysis of the same vessels was repeated in the second step (E2). In all analyzed vessels, the following variables were collected: peak systolic velocity (PSV); end diastolic velocity (EDV); average velocity $(\mathrm{AV})$; pulsatility index (PI); resistance index (RI). The three last ones were collected by means of a formula (Excel 2010 software). Studies report that the reference values for normal adults are as the following arteries and variables: VA: 20-68 in PSV, 9-33 in EDV, 16-48 in AV; BA: 35-87 in PSV, 16-44 in EDV, 25-62 in AV, ICA: 54-90 in PSV, 21-31 in EDV, 32-46 in $\mathrm{AV}^{12,25}$.

\section{Rest for the control group}

Controlled by operator-2, the subject was instructed to relax and rest for 5 minutes.

\section{OM-CRAT}

In EG-1 and EG-2, the OM-CRAT was performed by operator-2, involving the subject's neck with the index finger next to each vertebra and its interface joint (posterior region of the transverse processes). Performing passive rhythmic and smooth movements with three repetitions for each interface joint (zygapophyseal joint), i.e., with mobilizations from one side to the other, associating lateral sliding with rotation, in a " $\infty$ " movement at the axial view. The process started with the first thoracic vertebra (T1) rising through all cervical vertebrae until the atlanto-occipital joint. On the upper cervical, three mobilizations in flexion, and three in bilateral extension of the occipital condyle were added (atlanto-occipital), plus three lateral sliding to the atlas, and three rotations to $\mathrm{C} 3$ and three rotations to $\mathrm{C} 2-\mathrm{C} 1$. For the atlanto-occipital, one of the hands was on the head of the subject (the frontal bone region) ${ }^{5}$.

This study was approved by the Research Ethics Committee (CEP-HC-UFPR: 2233.127/2010-06) and is in compliance with the Declaration of Helsinki.

\section{Statistical analysis}

The statistical analysis used the Student's $t$-test (average and standard deviation), ANOVA One Way and TUKEY (post-hoc) (to compare the three groups) and Kolmogorov-Smirnov (for the normality test of the three groups). The program used for calculation was Excel 2010.

\section{RESULTS}

Table 1 shows, in the CG, the result of the Student's t-test with a significance level of $0.05(5 \%)$, where there was a significant dif-

Table 1. Comparison between the averages of the flow speed of the tests 1 and 2 in the control group ( $\mathrm{n}=29$ with mild to moderate neck pain)

\begin{tabular}{|c|c|c|c|c|c|c|c|}
\hline \multirow[t]{2}{*}{ Vessel and side } & \multirow[t]{2}{*}{ Flow speed } & \multicolumn{2}{|c|}{ Average $(\mathrm{cm} / \mathrm{s})$} & \multicolumn{2}{|c|}{ Standard deviation } & \multirow[t]{2}{*}{ Statistics $t$} & \multirow[t]{2}{*}{$p$ value } \\
\hline & & E1: Pre-rest & E2: Post-rest & E1: Pre-rest & E2: Post-rest & & \\
\hline \multirow[t]{3}{*}{ R Extra VA } & PSV & 48.79 & 47.28 & 16.35 & 19.48 & 0.62 & 0.5419 \\
\hline & EDV & 15.90 & 15.55 & 6.90 & 7.39 & 0.41 & 0.6824 \\
\hline & $\mathrm{AV}$ & 26.86 & 26.13 & 9.68 & 10.89 & 0.57 & 0.5748 \\
\hline \multirow[t]{3}{*}{ L Extra VA } & PSV & 53.93 & 50.38 & 12.90 & 13.01 & 2.13 & ${ }^{*} 0.0422$ \\
\hline & EDV & 17.72 & 16.83 & 6.93 & 5.82 & 1.14 & 0.2623 \\
\hline & AV & 29.79 & 28.01 & 8.51 & 7.76 & 1.82 & 0.0799 \\
\hline \multirow[t]{3}{*}{ R Intra VA } & PSV & 47.11 & 47.54 & 10.90 & 11.88 & -0.30 & 0.7653 \\
\hline & EDV & 22.96 & 23.18 & 5.79 & 5.84 & -0.29 & 0.7740 \\
\hline & AV & 31.01 & 31.30 & 7.31 & 7.73 & -0.30 & 0.76 \\
\hline \multirow[t]{3}{*}{ L Intra VA } & PSV & 55.52 & 55.48 & 14.81 & 14.77 & 0.02 & 0.9844 \\
\hline & EDV & 26.59 & 27.59 & 7.50 & 8.13 & -1.22 & 0.2328 \\
\hline & $\mathrm{AV}$ & 36.23 & 36.89 & 9.72 & 10.18 & -0.61 & 0.5489 \\
\hline \multirow[t]{3}{*}{ BA } & PSV & 62.76 & 63.31 & 14.92 & 15.83 & -0.35 & 0.7316 \\
\hline & EDV & 29.07 & 29.48 & 7.10 & 7.11 & -0.58 & 0.5655 \\
\hline & AV & 37.83 & 37.79 & 10.23 & 10.59 & 0.04 & 0.9693 \\
\hline \multirow[t]{3}{*}{ R ICA } & PSV & 82.70 & 73.95 & 25.42 & 19.56 & 1.96 & 0.0654 \\
\hline & EDV & 28.25 & 28.25 & 7.02 & 8.84 & 0.00 & 1.0000 \\
\hline & $\mathrm{AV}$ & 46.40 & 43.48 & 11.12 & 10.42 & 1.30 & 0.2082 \\
\hline \multirow[t]{3}{*}{ L ICA } & PSV & 81.35 & 79.25 & 19.53 & 17.76 & 0.52 & 0.6083 \\
\hline & EDV & 29.80 & 28.65 & 8.82 & 6.78 & 0.81 & 0.4287 \\
\hline & $\mathrm{AV}$ & 46.98 & 45.52 & 11.49 & 9.38 & 0.75 & 0.4595 \\
\hline
\end{tabular}

$\mathrm{R}=$ right side; $\mathrm{L}=$ left side; Extra VA = extracranial vertebral artery; Intra VA = intracranial vertebral artery; $\mathrm{BA}=$ basilar artery; ICA = internal carotid artery; E1 = test $1 ; \mathrm{E} 2$ = test 2 or post-rest; PSV = peak systolic velocity; EDV = end diastolic velocity, AV = average velocity. 
ference in the reduction of BFV (in PSV) only in the left extracranial VA, comparing the average of BFV variables before (E1) and after rest (E2 or ECR). If the other variables are considered, the reduction is remarkable, with no statistical significance of the BFV in the extracranial VA and ICA on both sides. RI and IP oscillations were below zero, with no statistical significance, and were excluded from the table to reduce its size.

Table 2 shows, in the EG-1, the result of the Student's t-test with a significance level of 0.05 (5\%), where there was a significant difference in the reduction of BFV (in EDV and AV) only in the right extracranial ICA, comparing the average of $\mathrm{BFV}$ variables before (E1) and after the OM-CRAT. One can notice a slight increase in the BFV in the right intracranial VA and BA, however with no statistical significance.

Table 3 shows, in the EG-2, the result of the Student's t-test with a significance level of 0.05 (5\%), where there was a significant difference in the increase of the BFV (in the EDV variable) in the right extra and intracranial VA, comparing the average of tests 1 and 2 of the EG-2. One notices that the other BFV variables follow the increase in the left VA and ICA, however with no statistical significance.

Table 4 shows that at the level of significance of 0.05 (5\%), in test 1 , all samples are acceptable as from the normal population or with normal flow speed.

Table 2. Comparison between the averages of the flow speed of the tests 1 and 2 in the experimental group- 1 ( $n=29$ with mild to moderate neck pain)

\begin{tabular}{|c|c|c|c|c|c|c|c|}
\hline \multirow{2}{*}{$\begin{array}{l}\text { Vessel and } \\
\text { side }\end{array}$} & \multirow[t]{2}{*}{ Flow speed } & \multicolumn{2}{|c|}{ Average $(\mathrm{cm} / \mathrm{s})$} & \multicolumn{2}{|c|}{ Standard deviation } & \multirow[t]{2}{*}{ Statistics $t$} & \multirow[t]{2}{*}{$p$-value } \\
\hline & & E1: Pre-OM-CRAT & E2: Post-OM-CRAT & E1: Pre-OM-CRAT & E2: Post-OM-CRAT & & \\
\hline \multirow[t]{3}{*}{ R Extra VA } & PSV & 54.59 & 48.10 & 17.72 & 13.62 & 1.97 & 0.0583 \\
\hline & EDV & 15.83 & 14.76 & 5.37 & 5.37 & 0.95 & 0.3488 \\
\hline & AV & 29.23 & 25.78 & 9.17 & 7.26 & 1.88 & 0.0712 \\
\hline \multirow[t]{3}{*}{ L Extra VA } & PSV & 53.03 & 52.52 & 11.45 & 15.86 & 0.23 & 0.8203 \\
\hline & EDV & 16.34 & 16.93 & 3.74 & 5.90 & -0.77 & 0.4498 \\
\hline & AV & 28.57 & 28.79 & 5.05 & 8.47 & -0.18 & 0.8558 \\
\hline \multirow[t]{3}{*}{ R Intra VA } & PSV & 50.55 & 52.10 & 13.14 & 11.39 & -1.00 & 0.3268 \\
\hline & EDV & 24.48 & 25.52 & 5.42 & 6.17 & -1.19 & 0.2445 \\
\hline & AV & 33.17 & 34.38 & 7.60 & 7.55 & -1.16 & 0.2577 \\
\hline \multirow[t]{3}{*}{ L Intra VA } & PSV & 57.00 & 55.14 & 12.63 & 12.32 & 1.19 & 0.2456 \\
\hline & EDV & 27.07 & 26.03 & 5.96 & 5.76 & 1.24 & 0.2268 \\
\hline & AV & 37.05 & 35.74 & 7.70 & 7.59 & 1.29 & 0.2059 \\
\hline \multirow[t]{3}{*}{ BA } & PSV & 65.59 & 67.03 & 11.63 & 16.40 & -0.61 & 0.5443 \\
\hline & EDV & 30.31 & 31.55 & 5.67 & 7.11 & -0.95 & 0.3521 \\
\hline & AV & 41.18 & 42.57 & 8.44 & 10.96 & -0.86 & 0.3962 \\
\hline \multirow[t]{3}{*}{ R ICA } & PSV & 80.08 & 78.88 & 20.87 & 24.55 & 0.38 & 0.7077 \\
\hline & EDV & 29.96 & 26.08 & 8.15 & 9.22 & 2.57 & ${ }^{*} 0.0167$ \\
\hline & $\mathrm{AV}$ & 46.67 & 43.68 & 11.16 & 11.95 & 2.17 & ${ }^{*} 0.0396$ \\
\hline \multirow[t]{3}{*}{ L ICA } & PSV & 84.35 & 83.77 & 21.93 & 24.19 & 0.17 & 0.8636 \\
\hline & EDV & 32.12 & 31.50 & 9.14 & 6.35 & 0.41 & 0.6832 \\
\hline & $\mathrm{AV}$ & 49.53 & 48.92 & 12.05 & 11.15 & 0.34 & 0.7401 \\
\hline
\end{tabular}

$\mathrm{R}=$ right side; $\mathrm{L}=$ left side; Extra VA = extracranial vertebral artery; Intra VA = intracranial vertebral artery; $\mathrm{BA}=$ basilar artery; ICA = internal carotid artery; $\mathrm{E} 1$ = tes 1 ; E2 = test 2 or post-rest; PSV = peak systolic velocity; EDV = end diastolic velocity, AV = average velocity.

Table 3. Comparison between the averages of tests 1 and 2 in the experimental group- $2(n=15$ with severe neck pain and occasional mild dizziness)

\begin{tabular}{|c|c|c|c|c|c|c|c|}
\hline \multirow{2}{*}{$\begin{array}{l}\text { Vessel and } \\
\text { side }\end{array}$} & \multirow[t]{2}{*}{ Flow speed } & \multicolumn{2}{|c|}{ Average $(\mathrm{cm} / \mathrm{s})$} & \multicolumn{2}{|c|}{ Standard deviation } & \multirow[t]{2}{*}{ Statistics $t$} & \multirow[t]{2}{*}{$p$-value } \\
\hline & & E1: Pre-OM-CRAT & E2: Post-OM-CRAT & E1: Pre-OM-CRAT & E2: Post-OM-CRAT & & \\
\hline \multirow[t]{3}{*}{ R Extra VA } & PSV & 51,93 & 52,20 & 14.43 & 12.85 & -0.101 & 0.9212 \\
\hline & EDV & 15.53 & 17.93 & 6.61 & 6.04 & -2.462 & ${ }^{*} 0.0274$ \\
\hline & $\mathrm{AV}$ & 27.67 & 29.36 & 8.62 & 7.97 & -1.212 & 0.2455 \\
\hline \multirow[t]{3}{*}{ L Extra VA } & PSV & 53.33 & 53.20 & 10.47 & 10.02 & 0.053 & 0.9583 \\
\hline & EDV & 18.13 & 18.73 & 3.93 & 4.32 & -0.609 & 0.5520 \\
\hline & $\mathrm{AV}$ & 29.87 & 30.22 & 5.79 & 5.74 & -0.251 & 0.8054 \\
\hline \multirow[t]{3}{*}{ R Intra VA } & PSV & 44.67 & 47.20 & 10.95 & 13.13 & -1.036 & 0.3178 \\
\hline & EDV & 21.13 & 23.73 & 5.38 & 6.86 & -2.295 & ${ }^{*} 0.0377$ \\
\hline & $A V$ & 28.98 & 31.56 & 7.13 & 8.89 & -1.661 & 0.1189 \\
\hline
\end{tabular}


Table 3. Comparison between the averages of tests 1 and 2 in the experimental group-2 ( $n=15$ with severe neck pain and occasional mild dizziness) - continuation

\begin{tabular}{|c|c|c|c|c|c|c|c|}
\hline \multirow{2}{*}{$\begin{array}{l}\text { Vessel and } \\
\text { side }\end{array}$} & \multirow[t]{2}{*}{ Flow speed } & \multicolumn{2}{|c|}{ Average $(\mathrm{cm} / \mathrm{s})$} & \multicolumn{2}{|c|}{ Standard deviation } & \multirow[t]{2}{*}{ Statistics $t$} & \multirow[t]{2}{*}{$p$-value } \\
\hline & & E1: Pre-OM-CRAT & E2: Post-OM-CRAT & E1: Pre-OM-CRAT & E2: Post-OM-CRAT & & \\
\hline \multirow[t]{2}{*}{ L Intra VA } & PSV & 55.87 & 53.00 & 15.24 & 14.25 & 1.747 & 0.1026 \\
\hline & $\mathrm{AV}$ & 35.78 & 33.89 & 9.01 & 9.76 & 1.387 & 0.1870 \\
\hline \multirow[t]{2}{*}{ BA } & PSV & 64.47 & 63.97 & 9.97 & 16.06 & 0.185 & 0.8559 \\
\hline & EDV & 28.93 & 29.47 & 5.09 & 6.72 & -0.327 & 0.7483 \\
\hline \multirow[t]{3}{*}{ R ICA } & PSV & 84.47 & 82.47 & 20.04 & 27.41 & 0.421 & 0.6801 \\
\hline & EDV & 34.80 & 32.60 & 8.70 & 9.55 & 0.880 & 0.3937 \\
\hline & $\mathrm{AV}$ & 51.36 & 49.22 & 11.75 & 15.15 & 0.707 & 0.4912 \\
\hline \multirow[t]{2}{*}{ L ICA } & PSV & 80.80 & 86.73 & 16.61 & 14.47 & -1.552 & 0.1431 \\
\hline & EDV & 36.13 & 35.60 & 7.73 & 11.10 & 0.221 & 0.8225 \\
\hline
\end{tabular}

$\mathrm{R}=$ right side; $\mathrm{L}=$ left side; Extra $\mathrm{VA}=$ extracranial vertebral artery; Intra $\mathrm{VA}$ = intracranial vertebral artery; $\mathrm{BA}=$ basilar artery; ICA = internal carotid artery; $\mathrm{E} 1$ = test 1 ; E2 = test 2 or post-rest; PSV = peak systolic velocity; EDV = end diastolic velocity, AV = average velocity.

Table 4. Kolmogorov-Smirnov Normality Test - Test 1

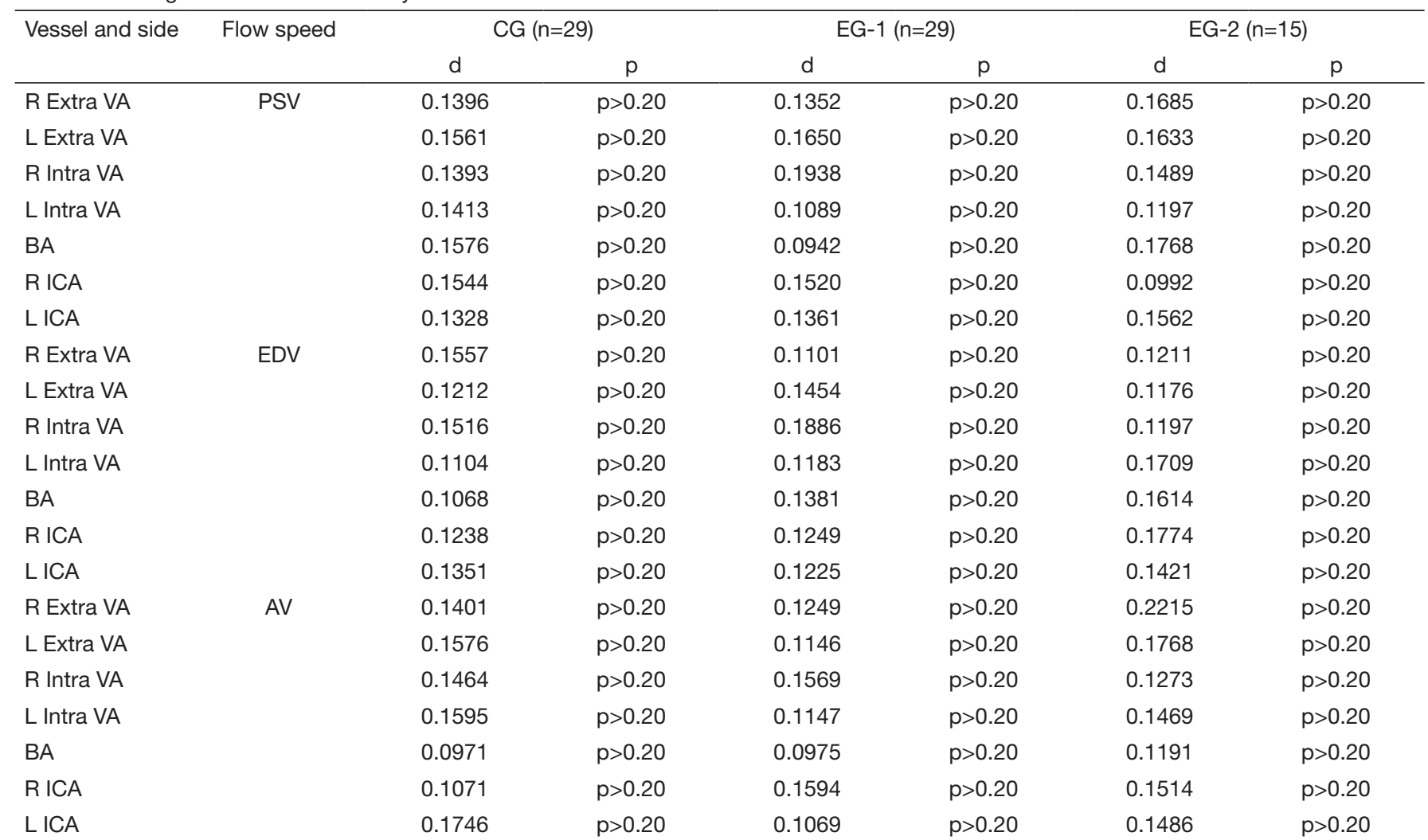

$\mathrm{CG}=$ control group $(n=29) ; E G-1=$ experimental group $1(n=29)$; EG-2 = experimental group $2(n=15) ; R=$ right side; $L=$ left side; Extra VA = extracranial vertebral artery; Intra VA = intracranial vertebral artery; BA = basilar artery; ICA = internal carotid artery; E1 = test 1; E2 = test 2 or post-rest; PSV = peak systolic velocity; EDV $=$ end diastolic velocity, $\mathrm{AV}=$ average velocity.

Table 5 shows that at the level of significance of $0.05(5 \%)$, in test 2 , all samples are acceptable as from the normal population or with normal flow speed.

Table 6 shows the comparison of the three groups (CG, EG1 , EG-2) in test 1, where there is a small significance only in the EDV of the right ICA in the CG with the EG-2 (Tukey test). The other arteries and variables did not show significant differences

Table 7 shows the comparison of the three groups (CG, EG-1, EG-2) in test 2, with significance only in the EDV of the left ICA in the CG with the EG-2. The other arteries and variables did not show significant differences. 
Table 5. Kolmogorov-Smirnov Normality Test - Test 2

\begin{tabular}{|c|c|c|c|c|c|c|c|}
\hline \multirow[t]{2}{*}{ Vessel and side } & \multirow[t]{2}{*}{ Flow speed } & \multicolumn{2}{|c|}{ CG $(n=29)$} & \multicolumn{2}{|c|}{$E G-1(n=29)$} & \multicolumn{2}{|c|}{ EG-2 $(n=15)$} \\
\hline & & d & $\mathrm{p}$ & d & $\mathrm{p}$ & $d$ & $\mathrm{p}$ \\
\hline R Extra VA & PSV & 0.1734 & $p>0.20$ & 0.1356 & $p>0.20$ & 0.0987 & $p>0.20$ \\
\hline L Extra VA & & 0.1706 & $p>0.20$ & 0.1650 & $p>0.20$ & 0.1292 & $p>0.20$ \\
\hline R Intra VA & & 0.1221 & $p>0.20$ & 0.1938 & $p>0.20$ & 0.2630 & $p>0.20$ \\
\hline L Intra VA & & 0.0628 & $p>0.20$ & 0.1089 & $p>0.20$ & 0.0962 & $p>0.20$ \\
\hline BA & & 0.1514 & $p>0.20$ & 0.0942 & $p>0.20$ & 0.1593 & $p>0.20$ \\
\hline L ICA & & 0.1289 & $p>0.20$ & 0.1361 & $p>0.20$ & 0.1711 & $p>0.20$ \\
\hline R Extra VA & EDV & 0.2213 & $p>0.10$ & 0.1101 & $p>0.20$ & 0.1136 & $p>0.20$ \\
\hline L Extra VA & & 0.1003 & $p>0.20$ & 0.1454 & $p>0.20$ & 0.1367 & $p>0.20$ \\
\hline R Intra VA & & 0.1227 & $p>0.20$ & 0.1886 & $p>0.20$ & 0.2178 & $p>0.20$ \\
\hline L Intra VA & & 0.1076 & $p>0.20$ & 0.1183 & $p>0.20$ & 0.1489 & $p>0.20$ \\
\hline L Extra VA & & 0.1386 & $p>0.20$ & 0.1146 & $p>0.20$ & 0.1362 & $p>0.20$ \\
\hline R Intra VA & & 0.1238 & $p>0.20$ & 0.1569 & $p>0.20$ & 0.2654 & $p>0.20$ \\
\hline L Intra VA & & 0.0687 & $p>0.20$ & 0.1147 & $p>0.20$ & 0.1745 & $p>0.20$ \\
\hline BA & & 0.1343 & $p>0.20$ & 0.0975 & $p>0.20$ & 0.1514 & $p>0.20$ \\
\hline R ICA & & 0.2296 & $p>0.20$ & 0.1594 & $p>0.20$ & 0.1409 & $p>0.20$ \\
\hline L ICA & & 0.1643 & $p>0.20$ & 0.1069 & $p>0.20$ & 0.1431 & $p>0.20$ \\
\hline
\end{tabular}

$\mathrm{CG}=$ control group $(n=29)$; EG-1 = experimental group $1(n=29)$; $E G-2=$ experimental group $2(n=15) ; R=$ right side; $L=$ left side; Extra VA = extracranial vertebra artery; Intra VA = intracranial vertebral artery; BA = basilar artery; ICA = internal carotid artery; E1 = test 1; E2 = test 2 or post-rest; PSV = peak systolic velocity; EDV $=$ end diastolic velocity, $\mathrm{AV}=$ average velocity.

Table 6. ANOVA and post-hoc test (Tukey test) - Test 1

\begin{tabular}{|c|c|c|c|c|c|c|}
\hline \multirow[t]{2}{*}{ Vessel and side } & \multirow[t]{2}{*}{ Flow speed } & \multicolumn{2}{|c|}{ ANOVA } & \multicolumn{3}{|c|}{ TUKEY - $p$} \\
\hline & & $\mathrm{F}$ & $p$ & CG and EG1 & CG and EG-2 & EG-1 and EG-2 \\
\hline R Extra VA & PSV & 0.89 & 0.4158 & 0.3824 & 0.8226 & 0.8698 \\
\hline R Intra VA & & 1.34 & 0.2683 & 0.5202 & 0.7972 & 0.2703 \\
\hline L Intra VA & & 0.09 & 0.9185 & 0.9152 & 0.9967 & 0.9653 \\
\hline BA & & 0.36 & 0.6998 & 0.6776 & 0.9073 & 0.9591 \\
\hline L ICA & & 0.16 & 0.8561 & 0.9482 & 0.9681 & 0.8477 \\
\hline R Extra VA & EDV & 0.02 & 0.9829 & 0.9991 & 0.9820 & 0.9882 \\
\hline L Extra VA & & 0.75 & 0.4749 & 0.5828 & 0.9679 & 0.5390 \\
\hline R Intra VA & & 1.83 & 0.1675 & 0.5600 & 0.5610 & 0.1480 \\
\hline L Intra VA & & 0.20 & 0.8192 & 0.9588 & 0.9142 & 0.8030 \\
\hline R Extra VA & $\mathrm{AV}$ & 0.48 & 0.6189 & 0.5965 & 0.9599 & 0.8568 \\
\hline L Extra VA & & 0.30 & 0.7452 & 0.7730 & 0.9995 & 0.8207 \\
\hline R Intra VA & & 1.67 & 0.1950 & 0.5157 & 0.6674 & 0.1827 \\
\hline L Intra VA & & 0.12 & 0.8881 & 0.9340 & 0.9859 & 0.8936 \\
\hline BA & & 1.16 & 0.3198 & 0.3264 & 0.5513 & 0.9887 \\
\hline R ICA & & 1.03 & 0.3543 & 0.9966 & 0.4093 & 0.4117 \\
\hline L ICA & & 0.35 & 0.7030 & 0.8641 & 0.6830 & 0.9119 \\
\hline
\end{tabular}

$\overline{C G}=$ control group $(n=29) ; E G-1=$ experimental group $1(n=29)$; EG-2 = experimental group $2(n=15) ; R=$ right side; $L=$ left side; Extra VA = extracranial vertebral artery; Intra VA = intracranial vertebral artery; BA = basilar artery; ICA = internal carotid artery; E1 = test 1; E2 = test 2 or post-rest; PSV = peak systolic velocity; EDV $=$ end diastolic velocity, $\mathrm{AV}=$ average velocity. 
Table 7. ANOVA and post-hoc test (Tukey test) - Test 2

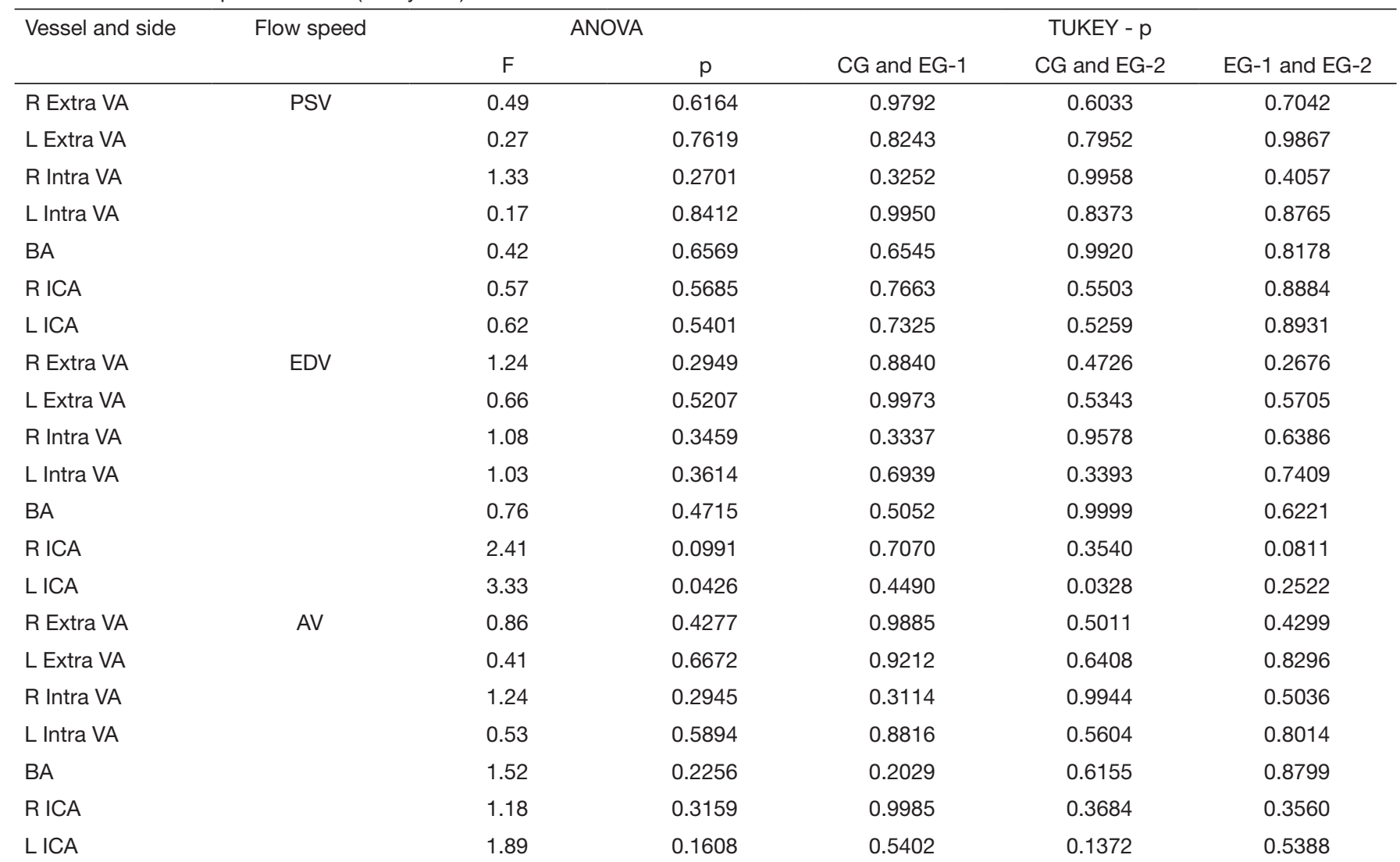

$\overline{C G}=$ control group ( $n=29)$; EG-1 = experimental group 1 ( $n=29)$; EG-2 = experimental group 2 ( $n=15$ ); $R=$ right side; $L=$ left side; Extra VA = extracranial vertebral artery; Intra VA = intracranial vertebral artery; BA = basilar artery; ICA = internal carotid artery; E1 = test 1; E2 = test 2 or post-rest; PSV = peak systolic velocity; EDV = end diastolic velocity, $\mathrm{AV}=$ average velocity.

\section{DISCUSSION}

In this study, the OM-CRAT was performed in several directions of joint mobilization, within the physiological limits of the cervical spine, but without using the extension positioning associated with rotation ${ }^{5,6}$.

The OM-CRAT increased the BFV in the cerebral circulation through the right VA and left CA (in EG-2, Table 3) and the right VA and BA (in the EG-1, Table 2), where other studies presented similar results ${ }^{5,15}$.

In the three groups, for tests 1 and 2 , all the samples were acceptable as from the normal population or with normal BFV (Tables 4 and 5), and the same result was confirmed in other studies in comparison with the normal population, but with no other therapy ${ }^{12,25}$. Thus, in this study, even with a small reduction in some BFV variables (Tables 1 and 2), one can see that there were no hypoflow or vascular insufficiency of the arteries examined by ultrasonography. Despite having significant BFV oscillations or not, the result of all the tables can be considered as normal variables of the BFV. Therefore, it is possible to state that OM-CRAT (with sliding and rotation) influences the $\mathrm{BFV}$ oscillations within the normality parameters in the three cervical-cerebral arteries (ICA, VA, BA), with no risks to the circulatory system to the population with mechanic neck pain of mild to severe intensity, with and without mild and occasional dizziness.
The results are also correlated with the references that the cervical vertebral manipulation does not cause undue injuries on the VA or CA, not being a risk factor or injury to the vertebrobasilar or carotid arteries $5,15,16,21-24$.

In a detailed analysis of the arteries and/or between one side and the other of the arteries (Tables 1, 2 and 3), it is noted that the $\mathrm{BFV}$ increases or decreases, generating flow compensations in the same moment.

Regarding EG-2, with a history of occasional dizziness related to the neck pain, it is in agreement with the descriptions of the references that mechanical neck pain can be associated to dizziness due to the mechanical vertebral dysfunction and to the pain that disturbs the innervation and the posture control system ${ }^{4,7-9}$. After the OM-CRAT, all individuals reported a sensation of well-being, relaxation and/or reduction in the neck pain.

As in other studies, the whiplash trauma due to a car accident is considered the main cause of VA and ICA injuries ${ }^{21,23}$. These cases require caution and investigation to know if cervical OM is contraindicated or not.

\section{STUDY LIMITATIONS}

The sample size was considered small for the duration of the study, and it should be taken into account the audience restriction due to the inclusion and exclusion criteria. The variables of 
the study that could interfere in the evaluation of the circulation and OM-CRAT were age, gender, physical fitness, anatomical differences of the arteries diameter, muscle-articular dysfunctions, cervical ROM and state of emotional stress.

\section{CONCLUSION}

The results of the vascular ultrasound showed that the BFV oscillations were within the normality parameters in patients submitted to OM-CRAT (EG-1 and EG-2) and at rest (CG).

\section{ACKNOWLEDGMENTS}

To the professionals of the scientific council of the Escuela de Osteopatía de Madrid, of the Post-graduation in Communication Disorders of the University of Tuiuti of Paraná, and the Research Ethics Committee of the General Hospital of the Federal University of Paraná. Also, to my friend Genoveva Freire D’ Aquino, my aunt Viviana R. Zurro and my beloved wife, Karin Teuber Stelle.

\section{REFERENCES}

1. Bevilagua-Grossi D, Pegoretti KS, Gonçalves MS, Speciali JG, Bordini CA, Bigal ME. Cervical mobility in women with migraine. Headache. 2009;49(5):726-31.

2. Rueda VG, Celis CL, López Meb, Uribarren AC, Tomás SC, García CH. Effectiveness of a specific manual approach to the suboccipital region in patients with chronic mechanical neck pain and rotation deficit in the upper cervical spine: study protocol for a randomized controlled trial. BMC Musculoskelet Disord. 2017;18:384.

3. Jørgensen MB, Skotte JH, Holtermann A, Sjøgaard G, Petersen NC, Søgaard K. Neck pain and postural balance among workers with high postural demands - a cross-sectional study. BMC Musculoskelet Disord. 2011;12:176.

4. Field S, Treleaven J, Jull G. Standing balance: a comparison between idiopathic and whiplash-induced neck pain. Man Ther 2008;13(3):183-91.

5. Stelle R, Zeigelboim BS, Lange MC, Marques JM. Influence of osteopathic manipulation on blood flow velocity of the cerebral circulation in chronic mechanical neck pain. Rev Dor. 2014:15(4):281-6.

6. Stelle R, Zeigelboim BS, Lange MC, Marques JM. Influence of manipulation at range of rotation of the cervical spine in chronic mechanical neck pain. Rev Dor. 2013:14(4):284-9.

7. Bielinska M, Olszewski J. Results evaluation in cervical vertigo kinesitherapy--preliminary report. Otolaryngol Pol. 2009;63(7):24-7. Polish.

8. Treleaven J. Sensorimotor disturbances in neck disorders affecting postural stability, head and eye movement control - Part 2: case studies. Man Ther. 2008;13(3):266-75.
9. Treleaven J. Sensorimotor disturbances in neck disorders affecting postural stability, head and eye movement control. Man Ther. 2008;13(1):2-11.

10. Thomas LC, Rivett DA, Bolton PS. Pre-manipulative testing and the use of the velocimeter. Man Ther. 2008;13(1):29-36.

11. Silva AL, Marinho MR, Gouveia FM, Silva JG, Ferreira AS, Cal R. Benign paroxysmal positional vertigo: comparison of two recent international guidelines. Braz J Otorhinolaryngol. 2011;77(2):191-200.

12. Barbosa MF, Abdala N, Carrete H Jr, Nogueira RG, Nalli DR, Fonseca JR, et al. [Reference values for measures of blood flow velocities and impedance indexes in healthy individuals through conventional transcranial Doppler]. Arq. Neuropsiquiatr. 2006;64(3B):829-38. Portuguese.

13. Galindez-Ibarbengoetxea X, Setuain I, Ramírez-Velez R, Andersen LL, González-Izal M, Jauregi A, et al. Short-term effects of manipulative treatment versus a therapeutic home exercise protocol for chronic cervical pain. A randomized clinical trial. J Back Musculoskelet Rehabil. 2018;31(1):133-45.

14. Cleland JA, Mintken PE, Carpenter K, Fritz JM, Glynn P, Whitman J, et al. Examination of a clinical prediction rule to identify patients with neck pain likely to benefit from thoracic spine thrust manipulation and a general cervical range of motion exercise: multi-center randomized clinical trial. Phys Ther. 2010;90(9):1239-50.

15. Creighton D, Kondratek M, Krauss J, Huijbregts P, Qu H. Ultrasound analysis of the vertebral artery during non-thrust cervical translatoric spinal manipulation. J Man Manip Ther. 2011;19(2):84-90.

16. Pérez-Llanes R, Ríos-Díaz J, Martínez-Payá JJ, Del-Banô-Aledo ME. Ultrasonography analysis of vertebral artery blood flow velocity changes on produced by the maximal cervical rotation. Fisioterapia. 2012;34(3):118-24.

17. Maduro-de-Camargo V, Alburquerque-Sendín F, Bérzin F, Cobos-Stefanelli V, Rodrigues-Pedroni C, Santos K. Immediate effects of the ashmore manipulation technique $\mathrm{C} 5 / \mathrm{C6}$, in muscle activity in patients with mechanical neck pain. Eur J Ost Clin Rel Res. 2012;7(1):2-9.

18. Orelli JG, Rebelatto JR. The effectiveness of manual therapy in individuals with headaches, with and without cervical degeneration: analysis of six cases. Rev Bras Fisioter. 2007;11(4):325-9.

19. Leon-Sanchez A, Cuetter A, Ferrer G. Cervical spine manipulation: an alternative medical procedure with potentially fatal complications. South Med J. 2007;100(2):201-3.

20. Mikkelsen R, Dalby RB, Hjort N, Simonsen CZ, Karabegovic S. Endovascular treatment of basilar artery thrombosis secondary to bilateral vertebral artery dissection with symptom onset following cervical spine manipulation therapy. Am J Case Rep. 2015;16:868-71.

21. Chung CL, Côte P, Stern P, L'Espérance G. The association between cervical spine manipulation and carotid artery dissection: a systematic review of the literature. J Manipulative Physiol Ther. 2015;38(9):672-6.

22. Herzog W, Leonard TR, Symons B, Tang C, Wuest S. Vertebral artery strains during high-speed, low amplitude cervical spinal manipulation. J Electromyogr Kinesiol. 2012;22(5):740-6

23. Haneline M, Triano J. Cervical artery dissection. A comparison of highly dynamic mechanisms: manipulation versus motor vehicle collision. J Manipulative Physio Ther. 2005;28(1):57-63.

24. Wynd S, Anderson T, Kawchuk G. Effect of cervical spine manipulation on a pre-existing vascular lesion within the canine vertebral artery. Cerebrovasc Dis. 2008;26(3):304-9.

25. Yazici B, Erdoğmuş B, Tugay A. Cerebral blood flow measurements of the extracrania carotid and vertebral arteries with Doppler ultrasonography in healthy adults. Diagn Interv Radiol. 2005;11(4):195-8. 